\title{
Lateral Load-carrying Capacity Research of Steel Plate Bearing in Space Frame Structure
}

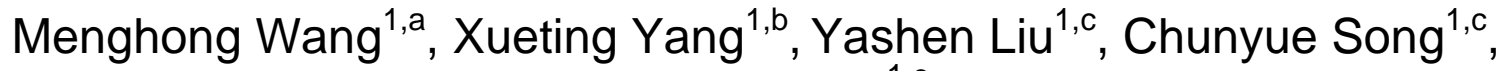 \\ Shanshan $\mathrm{Shi}^{1, \mathrm{C}}$ \\ ${ }^{1}$ School of Civil and Transportation Engineering, Beijing University of Civil Engineering and \\ Architecture, Beijing, China \\ awangmh@bucea.edu.cn, byxt262126549@163.com, chdlys1314@163.com
}

Keywords: bearing node; failure mode analysis; lateral load-carrying capacity

\begin{abstract}
For the lateral load-carrying capacity of steel plate bearing in space frame structure, there is not a specific formula for calculating the ultimate load capacity in current specification. Although the thickness of the base plate is verified, the possible dangerous points and failure mode of the bearing are not described in specification. In practical engineering design, the bearing is always designed by experience. Therefore, in order to accurately design the bearing, in this paper, the bearing node model was established by the finite element software ABAQUS. Then, failure mode and dangerous points of the bearing were analyzed under the action of lateral force. Finally, the formulas of load-carrying capacity of the bearing node were proposed, which providing theoretical basis for engineering design.
\end{abstract}

\section{Introduction}

With the development of our country, the large span steel structures of space structures are more and more applied, such as the roof structures of gymnasium, railway stations and exhibition halls. In grid structures, bearing is a very important part. It transfers the load from upper structures to foundation or corresponding substructures. ${ }^{[]}$If the design is not reasonable it may even cause accidents which can result in economic and personnel casualties.

Few specialized documents mentioned to the load-carrying capacity of steel plate bearing in network frame structure at present. The provision of load-carrying capacity is very simple. Under the action of horizontal tension, the specification only has verified the load-carrying capacity of anchor bolt but has not verified the ribbed slab and floor. Therefore, it has an important guiding significance for the design of bearing node to research the failure mode and load-carrying capacity of plate support under lateral tension.

\section{The Lateral Load-carrying Capacity of Spherical Center}

The Establishment of the Finite Element Model. In order to analyze the load-carrying capacity of bearing node, we should clearly learn the bearing model and boundary condition. The load lay on the spherical center of bolt-sphere, and the coordinate system is based on the bottom of the center of backing plate. For the bearing node whose bolt diameter is 30, the C3D8I which is a hexahedral linear non-coordinated unit was used in the contacted area. For the other area, the unit of C3D8R was used. The total number of the structural units is 29519.At the same time a "hard-contact" system was used in the normal for the contacted properties. The penalty function method which can improve the efficiency was used to solve the problem.

The Failure Modes of Spherical Center Under Horizontal Tension. In order to research the failure modes of nodes under horizontal tension, we put a horizontal load on the spherical center and then use the ABAQUS to analyze its non-linear finite elements. Fig.1 shows us its failure process along with the load increasing. 


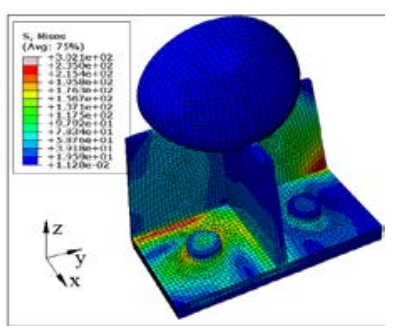

(1) Begin to enter the plastic zone

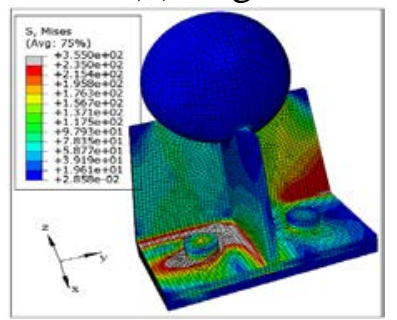

(3) The plastic zone continues to develop deeply

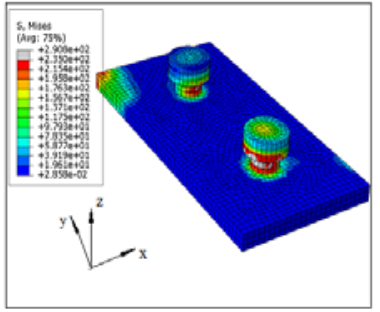

Fig.1 The failure modes under lateral tension

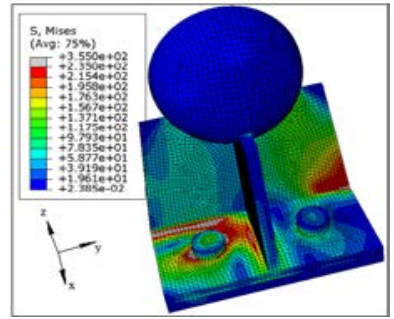

(2) The plastic zone continues to develop
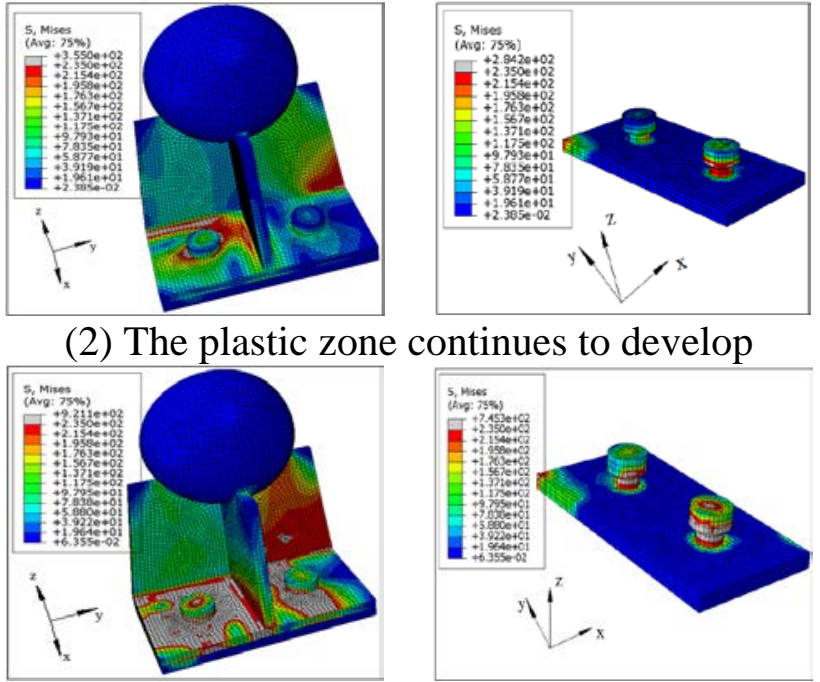

(4) Structure failure

In order to express its failure process clearly ,Fig.2 (1) - (4) show us the development progress of the floor plastic zone.Fig.2(1) shows us the first batch of the plastic hinge line. Duo to the pull force that ribbed slab applied on the floor , the floor which is located on either side of the ribbed slab firstly entered to the plastic zone. As the load increases, Fig.2(2) shows that the second batch of the plastic zone developed to the bolt along the center of floor.At the same time ,the ribbed slab and floor's border position part entered to the plastic.For Fig.2 (3),the plastic zone continues to develop vertically from the bolt center to a side of ribbed slab.With the load increasing, Fig.2(4) shows that most parts of the floor entered to the plastic zone, so we consider that the structure has failed. The area near the line $0-0$ came into yield situation.It is the center of the force balance.

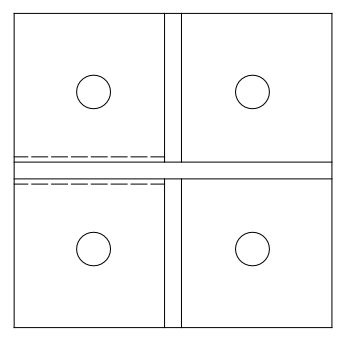

(1)The first batch of the plastic zone

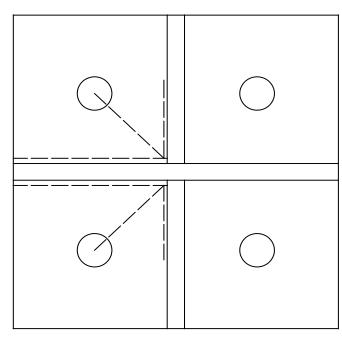

(2)The second batch of the plastic zone

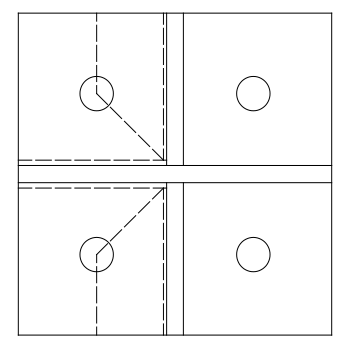

(3)The third batch of the plastic zone

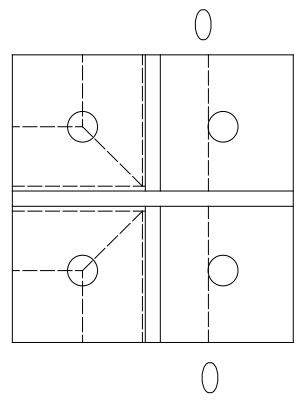

(4)The final batch of the plastic zone

Fig. 2 The development progress of floor plastic zone under horizontal tension

\section{The Calculation of Lateral Load-carrying Capacity}

According to the research above, the first batch of the plastic zone appeared in the floor, the bottom of the ribbed slab and the bolt bar. So we only need to research these three positions and to find out whose lateral load-carrying capacity is the minimum.

The Load-carrying Capacity of the Floor. We assume that the center of moment balance located in the bolt which is under the horizontal force. According to the moment balance, we can conclude that the expression of the maximum tension of a single bolt is:

$$
F_{t}=\frac{F_{Y}\left(h_{0}+50+e\right)}{2 c} \text {. }
$$

We define that $\mathrm{F}_{\mathrm{Y}}$ is the horizontal pulling force in $\mathrm{Y}$ direction, $\mathrm{F}_{\mathrm{t}}$ is the tension of a single bolt, $\mathrm{h}_{0}$ is the height of the ribbed slab, e is the thickness of the floor and $\mathrm{c}$ is the center distance of the bolt. We consider that $F_{t}$ is equal to a distribution force which is located in a plate whose two adjacent sides are fixed and the two pairs of edge is cantilever. So we can get: 


$$
\begin{aligned}
& q=\frac{F_{t}}{A_{0}} . \\
& \frac{\alpha q a_{1}^{2}}{e^{2} / 6} \leq f .
\end{aligned}
$$

We define that " $\alpha=0.06$ " is the maximum bending moment coefficient of the plate, $A_{0}$ is the area of the floor except for the bolt hole. So the expression of lateral load -carrying capacity is:

$$
F_{Y} \leq \frac{A_{0} c e^{2}}{3 \alpha\left(h_{0}+h_{1}+e\right) a_{1}^{2}} f \text {. }
$$

In order to ensure the load-carrying capacity of the bolt we should verify its safety when it is under the action of tension and shear.

$$
\left\{\begin{array}{l}
\sqrt{\left(\frac{F_{Y}}{4 N_{v}^{b}}\right)^{2}+\left(\frac{F_{t}}{N_{t}^{b}}\right)^{2}} \leq 1 \\
\frac{F_{Y}}{4} \leq N_{c}^{b}
\end{array} .\right.
$$

In this expression $N_{v}^{b}$ is the shear-bearing capacity of a single bolt and $N_{t}^{b}$ is the tension-bearing capacity. Moreover, $N_{c}^{b}$ is the load-carrying capacity of the floor.

\section{The compression-carrying capacity of the ribbed slab.}

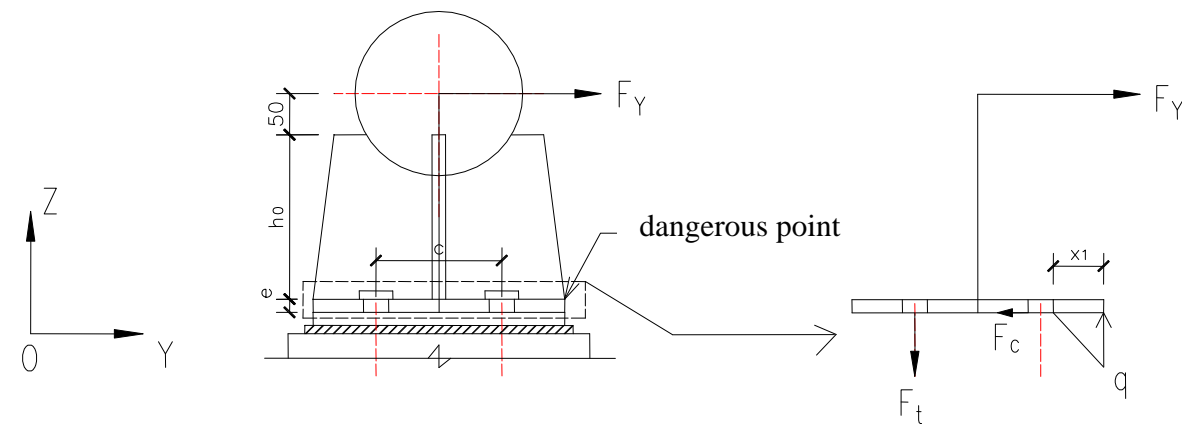

Fig.3 The dangerous positions of the ribbed slab under compression

Take a moment to the tensile bolt center, we can get the expression of load-carrying capacity is:

$$
\begin{aligned}
& F_{Y}\left(h_{0}+50+e\right)=\frac{1}{2} x_{1} q\left(c+\frac{d}{2}+\frac{2}{3} x_{1}\right) . \\
& x_{1}=\frac{a-c}{2}-\frac{d}{2} .
\end{aligned}
$$

For $\mathrm{a}$ is the length of the floor, $\mathrm{c}$ is the bolt spacing, $\mathrm{d}$ is the bolt diameter, $\mathrm{q}$ is the maximum distributed load on the outer edge, $F_{t}$ is the tension of the bolt, $F_{c}$ is the extrusion that compressed bolt applied on the floor.

$$
F_{Y} \leq \frac{\frac{1}{2} q[(a-c) / 2-d / 2](2 c / 3+d / 6+a / 3)}{h_{0}+50+e}
$$

(8) slab.

In this formula, $\mathrm{q}$ is corresponding to the maximum stress $\sigma$, and $\mathrm{t}$ is the thickness of the ribbed

$$
\sigma=\frac{q}{t} \leq f .
$$




$$
F_{Y} \leq \frac{\frac{1}{2} f t[(\mathrm{a}-\mathrm{c}) / 2-d / 2](2 c / 3+d / 6+a / 3)}{h_{0}+50+e}
$$

The load-carrying capacity of the interface for bolt sphere and ribbed slab. We consider that the strength of the weld and the steel are same. We consider that the arc ,which is the bolt sphere and the ribbed slab's intersection, is equal to a rectangular area, as the shadow area of Fig.4. At the same time, we conservatively consider that the force bearing by the bolt sphere and the ribbed slab's intersection can be ignored.

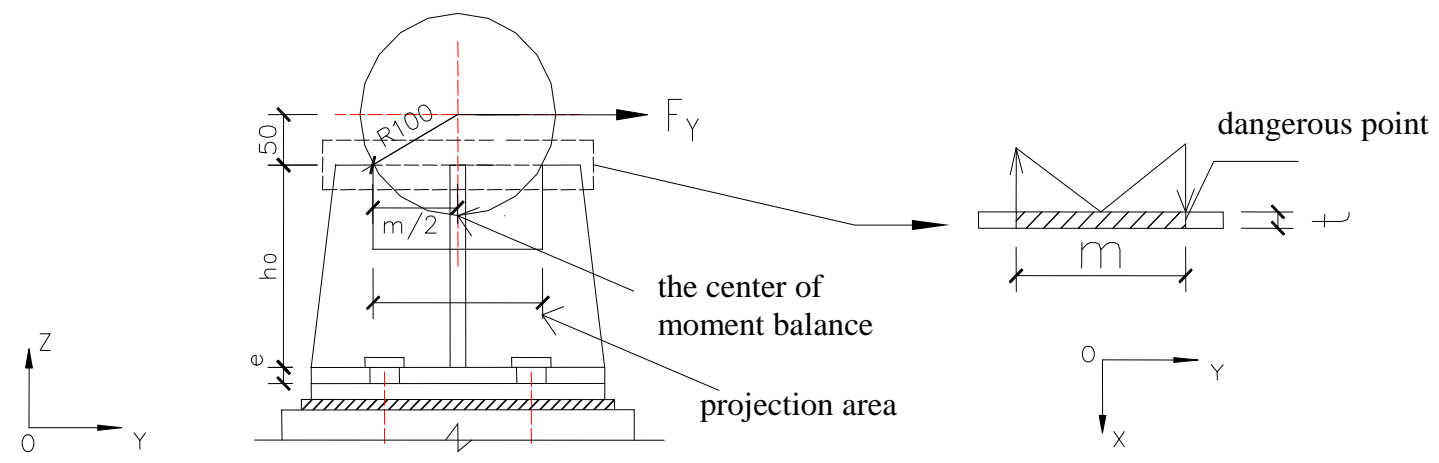

Fig.4 Bolt ball and ribbed slab border

The vertical distance from the sphere center to the top of ribbed slab is defined as $h_{1}, m$ is the length of the projection area The formula for calculating this weld is:

$$
\begin{aligned}
& m=2 \sqrt{R^{2}-h_{1}^{2}} . \\
& \frac{F_{Y} R}{\mathrm{tm}^{2} / 6} \leq f .
\end{aligned}
$$

So we can conclude that the expression of lateral load-carrying capacity is:

$$
F_{Y} \leq \frac{t m^{2}}{6 R} f \text {. }
$$

From what has been discussed, the expression of the lateral load-carrying capacity of bearing node is the minimum situation what we have discussed. The expression is Eq.4, Eq.10, and Eq.13.

We should verify its safety when it is under the action of tension and shear. Plugging Eq.5 into Eq.6, we can get the shear-carrying capacity expression of bolt:

$$
\left\{\begin{array}{l}
F_{b} \leq \sqrt{\frac{1}{1 / 16\left(N_{v}^{b}\right)^{2}+\left(h_{0}+50+e\right)^{2} / 4 c^{2}\left(N_{t}^{b}\right)^{2}}} . \\
F_{y} \leq 4 N_{c}^{b}
\end{array}\right.
$$

\section{The Finite Element Validation}

In order to verify the load-carrying capacity expression is right, we should analyze it in variable parameters. In this article, we use ABAQUS to analyze it. The results are followed in Table 1.

Table 1 The lateral load-carrying capacity

\begin{tabular}{ccccccccc}
\hline $\begin{array}{c}\mathrm{D} \\
(\mathrm{mm})\end{array}$ & $\begin{array}{c}\mathrm{F}_{1} \\
(\mathrm{kN})\end{array}$ & $\begin{array}{c}\mathrm{F}_{2} \\
(\mathrm{kN})\end{array}$ & $\begin{array}{c}\mathrm{F}_{3} \\
(\mathrm{kN})\end{array}$ & $\begin{array}{c}\mathrm{F}_{\mathrm{h}} \\
(\mathrm{kN})\end{array}$ & $\begin{array}{c}\mathrm{F}_{\mathrm{c}} \\
(\mathrm{kN})\end{array}$ & $\begin{array}{c}\mathrm{F}_{\mathrm{Y}} \\
(\mathrm{kN})\end{array}$ & $\mathrm{F}_{\mathrm{FEM}}$ & $\mathrm{F}_{\mathrm{FEM}} / \mathrm{F}_{\mathrm{Y}}$ \\
\hline 30 & 90.93 & 86.93 & 187.99 & 82.59 & 902.40 & 82.58 & 111.25 & 1.347 \\
42 & 179.35 & 188.34 & 234.99 & 200.33 & 1579.2 & 179.35 & 201.15 & 1.122 \\
56 & 280.54 & 303.24 & 293.73 & 366.85 & 2632.0 & 280.54 & 354.11 & 1.262 \\
\hline
\end{tabular}


Note: $F_{1}$ is the bearing capacity of the floor when it is yield, $F_{2}$ is the bearing capacity of the ribbed slab when the lower yield, $\mathrm{F}_{3}$ is the bearing capacity between upper ribbed slab and bolt ball when it is yield, $\mathrm{F}_{\mathrm{b}}$ is the bearing capacity of bolt when it is yield under tension and shear, $\mathrm{F}_{\mathrm{c}}$ is the bearing capacity of the bolt hole wall when it is yield under extrusion, $\mathrm{F}_{\mathrm{Y}}$ is the lateral load-carrying capacity which is the minimum of them.

The Table 1 tells us that the safety factor obtained by formula and ABAQUS is bigger than '1'.So the formula proposed by this article is reasonable.

\section{Conclusions}

This article have researched the failure mode of steel plate bearing in space frame structure, put forward the formula for calculating the ultimate bearing capacity and validated the applicability of them. This article will provide a theoretical basis for the design of rack and the revision of specification.

\section{Acknowledgements}

This work was financially supported by Beijing National Science Foundation (8132023), Engineering Research Center of Scientific and Technological Achievements Transforming - Beijng Higher Institution Engineering Research Center of Structural Engineering and New Material (02058214001) , BUCEA Urban Rural Construction and Management Industry Research Development Collaboration Post Graduate Training Centre.

\section{References}

[1] M.H. Wang, in: Nonlinear Analysis and Research on Dynamic Stability of Steel Structure, Architecture and Building Press, China 2011.

[2] Code for design of steel structure (GB50017-2003).

[3] Technology specification for space frame structures (JGJ 7-2010).

[4] M.H. Wang and J.P. Hao, in: Treatment of Elastic Boundary in Steel Space Frame, Building Technique Development Publishing, Beijing 2002.

[5] S.F. Chen and Q. Gu: Steel structure (China architecture \& building press, Beijing 2007). 